\title{
Self-presentation Tactics in Social Media
}

\author{
Han-Yun HUANG
}

School of Journalism and Communication, Xiamen University, Fujian, China.

\section{Keywords: Self-presentation, Social Media, Adolescents}

\begin{abstract}
Social media now are very popular. Many people use them everywhere through mobile phones. One of the most important motives people using social media is for self-presentation. This study focuses on discussing the self-presentation tactics adolescents use in social media. The results show that adolescents mainly use four self-presentation tactics in social media, namely, self-promotion, ingratiation, manipulation and damage control. These four self-presentation tactics will be discussed in details.
\end{abstract}

\section{Introduction}

Social media are applications that enable people to interact with each other and build social networks that increase social capital (Barnes, 2008). Kaplan and Haenlein (2010) defined social media more theoretically as "a group of Internet-based applications that build on the ideological and technological foundations of Web 2.0, which allow the creation and exchange of user-generated content" (p. 64). Spannerworks (2007) gave a similar working definition of social media as new kinds of online media that share most or all of the characteristics of participation, openness, conversation, community and connectedness. Comm (2010) suggested that the "social" part of social media means that "publishing is now about participation" (Comm, 2010, p. 3). Those who use social media sufficiently create not only content, but also conversations, and those conversations combine further to create communities (Comm, 2010).

Results from focus groups among adolescents in urban China indicated that IM, SNS, blogs, and microblogs were their four most widely used social media. These results were absolutely in accord with the statistics reported by CNNIC showing that in 2011 and 2012, IM, blogs, microblogs, and SNS were the four most popular online communication applications among adolescents in China (CNNIC, 2012, 2013). Therefore, the social media this study focuses on consist of IM, SNS, blogs, and microblogs.

\section{Literature Review}

\section{Self-Presentation}

Goffman (1959) was among the first to acknowledge that individuals need to present themselves to others as an acceptable person. He described how the self-as-performer has a basic motivational core, and how people can be strategic in managing the impression they give. Individuals wear masks, play roles and present themselves in the ways they see themselves or in the ways they desire to be seen by others (Goffman, 1959). They engage in complex intra-self negotiations in order to project a desired impression and maintain it through consistently performing coherent and complementary behaviors (Schlenker, 1980; Schneider, 1981).

Gilmore and his colleagues defined impression management as "conscious or unconscious attempts to influence images during interaction" (Gilmore, Stevens, Harrell-Cook \& Ferris, 1999, p. 322). Individuals manage their impressions when they wish to present a favorable image of themselves to others (Bolino, Kacmar, Turnley \& Gilstrap, 2008). Thus, the concept of impression management is based on the assumption that individuals have an inherent need to be accepted and included, and therefore act accordingly (Leary, 1996). Self-presentation serves the goal of impression management (Goffman, 1959). Therefore these two concepts are inseparable and 
interchangeable (Tedeschi \& Riess, 1981).

Jones and Pittman (1982) proposed that individuals typically use five self-presentation tactics: self-promotion, ingratiation, supplication, intimidation and exemplification (Jones \& Pittman, 1982). The opportunity to manage impressions has been advanced by new communication technologies (Walther, 1993). In the Internet era, people can make and remake themselves, choosing the details of their online impression (Mnookin, 1996). Adolescents now can manage the impression they make through social media in many ways. These impression management opportunities come with the visual anonymity of the social media, providing users much greater degrees of freedom (Joinson, 2003). People can manipulate various characteristics online to present themselves as more humorous, more friendly, or more likable than in daily life (Chester, 2004). Dominick (1999) found that the five impression management tactics proposed by Jones and Pittman (1982) in offline communication extended to the online setting of personal home pages.

One feature that distinguishes online self-presentation from self-presentation in daily life lies in the full control users have over their published information, allowing the self-presentation to be more strategic (Kramer \& Winter, 2008). Online self-presentation can be based on longer and more systematic considerations than in a lively self-presentation (Leary, 1996). Thus, users can highlight certain aspects of themselves (Marwick, 2005) or think about which photos convey the best images of themselves (Ellison, Heino, \& Gibbs, 2006). Studies showed that people tend to exaggerate and are not always honest when they present themselves online. For example, "Fakesters" publish fake profile information in SNS and pretend to be more interesting and successful (Boyd, 2004). Some individuals just switch between their "real" self and their "fake" self on SNS (Jung, Youn, \& McClung, 2007).

Thus, users actively participate in SNS to manage their impression (Kramer \& Winter, 2008). Indeed, social media provide an ideal place for self-presentation. In IM, users can manage their impression through chatting with others, trying to be more humorous, more interesting, or more knowledgeable. They can also provide an explanation to friends through IM if they did something wrong or deliver an apology if they hurt others. In SNS, users can manage their impression by creating personal profiles, uploading photos, writing on others' wall, or commenting on others' files. In blogs and microblogs, users can manage their impression through writing diaries, sharing their personal lives everywhere, or showing their care and friendliness to friends by commenting on others' blogs or microblogs.

Similar to Jones and Pittman (1982), Jung, Youn, and McClung (2007) discussed four self-presentation tactics in blogs: 1) demonstration of competence revealing that the bloggers showed their abilities, performance, and qualifications indirectly; 2) supplication indicating that the bloggers deprecated themselves indirectly and showed weakness to others; (3) exemplification showing that the bloggers tend to be self-disciplined and devoted to others; and 4) ingratiation demostrating that the bloggers showed humor and familiarity in the blogs. Rosenberg (2009) also studied the management of online impressions, and identified four self-presentation tactics used in Facebook: manipulation, damage control, self-promotion, and role model.

Many other features might also contribute to online self-presentation in social media. For example, more friends presented on one's profile leads to a positive evaluation; popularity and pleasantness were greater when profile owners had a larger number of linked friends (Kleck, Reese, Behnken, and Sundar, 2007).

Based on the previous literature, this study asks:

RQ: What self-presentation tactics are used by adolescents for in social media?

\section{Research Method}

\section{Participants and sampling procedure}

Survey was executed among a multi-stage cluster sampling among adolescents in urban China. First, five developed urban cities-Beijing, Shanghai, Guangzhou, Shenzhen, and Xiamen — were 
chosen in China. Second, middle schools were selected in each of the five cities, with one each from Beijing, Shanghai and Xiamen, and two each from Guangzhou and Shenzhen. Finally, in each selected middle school, one or two classes were randomly chosen in each grade that school has, totaling 45 classes. One day before the survey, a notification was distributed among the students in these randomly selected classes. The participation was permitted by their parents.

As a whole, a total of 2,038 questionnaires were distributed in class among seven middle schools in these five major metropolitan cities. The final sample consisted of 1,549 completed surveys and the response rate was $76.0 \%$.

\section{Measures}

The modified Self-Presentation Tactics Scale (Lee, Quigley, Nesler, Corbett, \& Tedeschi, 1999) was used. Self-presentation tactics are behaviors for impression management to achieve interpersonal goals (Lee et al., 1999). This scale was used to assess various tactics associated with self-presentation. Rosenberg (2009) modified it to measure individuals' self-presentation on Facebook. Again, the scale was modified in this study to make it suitable for the measuring of Chinese adolescents' competence of self-presentation tactics on social media. The respondents were asked to respond on a 5-point Likert-type scale ranging from 1 (very infrequently) to 5 (very frequently) to 12 items as follows: (1) I share my good scores or positive accomplishments with friends in social media; (2) I share my daily or travel photos on which I look good with friends in social media; (3) I make my friends know my strengths through social media; (4) I praise my friends in social media so that they will see me as friendly; (5) I compliment the experiences of my friends in social media so that they are willing to share their experiences with me; (6) I pay attention to my friends in social media so that they would think I care about them; (7) When I'm blamed for something, I make excuses on social media; (8) When I do not get a good grade, I explain in social media that it is not all my fault; (9) I depreciate my rival on social media; (10) If I have done something wrong, I will apologize to my friends through social media; (11) If I hurt my friends, I will apologize to them through social media; and (12) I offer explanations or justify my behavior for negative events in social media to reduce the negative impression others have of me. A factor analysis yielded four self-presentation tactics in social media for adolescents, which will be discussed in detail below.

\section{Results}

The research question asked about self-presentation tactics adolescents use in social media. To answer it, principal component factor analysis was run, and it yielded four self-presentation tactics adolescents used in social media, which accounted for $75.47 \%$ of total variance. As shown in Table 1 , the first tactic, "ingratiation" ( $\alpha=.87$; eigenvalue $=4.43$; explained $22.70 \%$ of the variance), consisted of three items. This tactic reflected adolescents paid attention to their friends, complimented their friends' experiences, and praised their friends in social media to show their friendliness and care. "Damage control," the second tactic $(\alpha=.85$; eigenvalue $=1.55$; explained $21.42 \%$ of the variance), included three items characterizing how adolescents reduced negative impressions on social media. Adolescents apologized to friends if they had done something wrong, or they offered explanations and/or justifications for negative or offensive behavior. "Manipulation," the third tactic ( $\alpha=.70$; eigenvalue $=1.42$; explained $16.80 \%$ of the variance), consisted of three items illustrating on social media, how adolescents might comment negatively about a rival, make excuses if blamed for something, or rationalize why they received a poor mark. The fourth tactic, "self-promotion" $(\alpha=.75$; eigenvalue $=.90$; explained $14.55 \%$ of the variance $)$, contained two items indicating that adolescents used social media to share good scores, positive accomplishments, or photos - such as day-to-day or vacation/travel photos-that made them look good. These four tactics revealed the competence of adolescents to present themselves or manage the impression others had of them using social media. Table 1 shows the factor loading. The 
self-presentation tactics identified from social media agree with traditional self-presentation skills used in face-to-face communication (Jones \& Pittman, 1982). They also confirm the self-presentation tactics Jung, Youn, and McClung (2007) found in blogs and Rosenberg (2009) identified in Facebook. Therefore, the results also confirm the previous literature that some adolescents are more competent than others in self-presentation tactics. Those who are good at online self-presentation have full control over their published information, so their online self-presentation can be more strategic (Kramer \& Winter, 2008) and based on longer and more systematic considerations than in face-to-face self-presentation (Leary, 1996).

Table 1 Factor Analysis of Impression Management Tactics among Adolescents

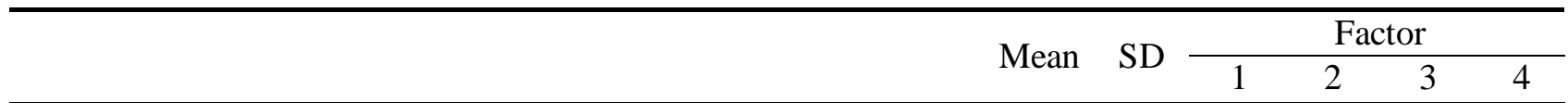

\section{Ingratiation}

1. I compliment the experiences of my friends in social media so that they are willing to share with me.

2. I praise my friends in social media so that they will see me as friendly.

$\begin{array}{lll}3.07 & 1.05 & .85 \\ 3.08 & 1.03 & .83 \\ 3.21 & .98 & .82\end{array}$

3. I pay attention to my friends in social media so that they would think I care about them.

\section{Damage Control}

4. If I hurt my friend, I will apologize to s/he through social media.

$\begin{array}{lll}3.37 & 1.16 & .91 \\ 3.26 & 1.14 & .89\end{array}$

through social media.

6. I offer explanations or justify my behavior for negative events in social media, so as to reduce the negative impression from others have of me.

\section{Manipulation}

7. When I don't get a good grade, I explain in social media that it's not all my faults.

$\begin{array}{rrr}2.10 & .98 & .84 \\ 1.77 & .96 & .82 \\ 2.69 & 1.06 & .60\end{array}$

8. I depreciate my rival on social media.

9. When I'm blamed for something, I make excuses on social media.

\section{Self-promotion}

10. I share my daily or travelling photos on which I look good with friends in social media.

11. I share my good scores or positive accomplishments with friends in social media.

Eigenvalues

Variance explained (\%)

Cronbach's alpha

$\begin{array}{llll}4.43 & 1.55 & 1.42 & .90\end{array}$

$\begin{array}{llll}22.70 & 21.42 & 16.80 & 14.55\end{array}$

$\begin{array}{llll}.87 & .85 & .70 & .75\end{array}$

Note. Scale: $1=$ very infrequently and $5=$ very frequently. Total variance: $75.47 \% . \mathrm{N}=1535$.

\section{References}

[1] Barnes, S. B. (2008). Understanding social media from the media ecological perspective. In E. A. Konijn, S. Utz, M. Tanis, \& S. B. Barnes (Eds.), Mediated Interpersonal Communication (pp.14-33). New York: Routledge. 
[2] Bolino, M. C., Kacmar, M. K., Turnley, W. H., \& Gilstrap, B. J. (2008). A multi-level review of impression management motives and behaviors. Journal of Management, 34(6), 1080-1190.

[3] Boyd, D. M. (2004, April). Friendster and publicly articulated social networks. Paper presented at Conference on Human Factors and Computing Systems, Vienna.

[4] Comm, J. (2010). Twitter Power 2.0: How to Dominate Your Market One Tweet at a Time. Hoboken, New Jersey: John Wiley \& Sons.

[5] Chester, A. (2004). Presenting the self in cyberspace: Identity play in MOOS. PhD thesis, Department of Philosophy. University of Melbourne, Melbourne, Australia.

[6] CNNIC (2012). Statistical Survey Report on China Youth Internet Behaviors 2011. Retrieved January 20, 2014, from http://www.cnnic.net.cn/hlwfzyj/hlwxzbg/ qsnbg/201208/P020120816403477216094.pdf

[7] CNNIC (2013). Statistical Survey Report on China Youth Internet Behaviors 2012. Retrieved January 20, 2014, from http://www.cnnic.net.cn/hlwfzyj/hlwxzbg/ qsnbg/201312/P020131225339891898596.pdf

[8] Dominick, J. R. (1999). Who do you think you are? Personal home pages and self-presentation on the World Wide Web. Journal of Mass Communication, 76(4), 646-658.

[9] Ellison, N., Heino, R., \& Gibbs, J. (2006). Managing impressions online: Self-presentation processes in the online dating environment. Journal of Computer-Mediated Communication, 11, 415-441.

[10] Gilmore, D. C., Stevens, C. K., Harrell-Cook, G., \& Ferris, G. R. (1999). Impression management tactics. In R. W. Eder \& M. M. Harris (Eds.), The employment interview handbook (pp. 321-336). London: Sage.

[11] Goffman, E. (1959). The presentation of self in everyday life. New York: Penguin Books.

[12] Jones, E. E., \& Pittman, T. S. (1982). Toward a general theory of strategic self-presentation. In J. Suls (Eds.), Psychological Perspectives on the Self (Vol. 1, pp. 231-262). Hillsdale, NJ: Lawrence Erlbaum.

[13] Joinson, A. N. (2003). Understanding the Psychology of Internet Behavior: Virtual worlds, real lives. Basingstoke, New York: Palgrave Macmillan.

[14] Jung, T., Youn, H., \& McClung, S. (2007). Motivations and self-presentation strategies on Korean-based "Cyworld" weblog format personal homepages. CyberPsychology and Behavior, 10(1), 24-31.

[15] Kaplan, A. M., \& Haenlein, M. (2010). Users of the world, unite! The challenges and opportunities of Social Media. Business Horizons, 53(1), 59-68.

[16] Kleck, C. A., Reese, C., Ziegerer-Behnken, D., \& Sandar, S. (2007). The company you keep and the image you project: Putting your best face forward in online social networks. Paper presented at the Annual Meeting of the International Communication Association, San Francisco, CA, United States.

[17] Kramer, N. C., \& Winter, S. (2008). Impression management 2.0. The relationship of self-esteem, extraversion, self-efficacy, and self-presentation within social network sites. Journal of Media Psychology, 20(3), 106-116.

[18]Leary, M. R. (1996). Self-presentation: Impression Management and Interpersonal Behavior. Boulder, CO: Westview Press. 
[19]Lee, S., Quigley, B. M., Nesler, M. S., Corbett, A. B., \& Tedeschi, J. T. (1999). Development of a self-presentation tactics scale. Personality and Individual Differences, 26, 701-722.

[20] Marwick, A. (2005, October). I'm a lot more interesting than a friendster profile: Identity, authenticity, and power in social networking services. Paper presented at the Conference of Association for Internet Researchers 6, Chicago, IL, United States.

[21] Mnookin, J. (1996). Virtual(ly) law: The emergence of law in LambdaMOO. Journal of Computer-Mediated Communication, 2(1), no page indicated.

[22] Rosenberg, J. (2009). Online impression management: personality traits and concern for secondary goals as predictors of self-presentation tactics on Facebook. Unpublished master's thesis. Kent State University, Ohio, USA.

[23] Spannerworks (2007). What is social media? Retrieved April 20, 2011, From http://www.icrossing.co.uk/fileadmin/uploads/eBooks/What_is_Social_Media_iCrossing_ebook.pd $\mathrm{f}$

[24] Schlenker, B. R. (1980). Impression Management: The Self-Concept, Social Identity, and Interpersonal Relationships. Monterey, CA: Brooks/Cole.

[25] Schneider, D. J. (1981). Tactical self-representations toward a broader conception. In J. Tedeschi (Eds.), Impression Management Theory and Social Psychological Research (pp. 23-40). New York: Academic Press.

[26] Tedeschi, J. T., \& Riess, M. (1981). Identities, the phenomenal self, and laboratory research. In J. T. Tedeschi (Eds.), Impression Management Theory and Social Psychology Research (pp. 3-22). New York: Academic Press.

[27] Walther, J. B. (1993). Impression development in computer-mediated interaction. Western Journal of Communication, 57, 381-398. 